\title{
SIGNIFICANTLY ELEVATED SYSTEMIC NEUTROPHIL REACTIVE OXYGEN INTERMEDIATES ARE ASSOCIATED WITH SEVERE NEONATAL ENCEPHALOPATHY
}

\author{
F. O'Hare ${ }^{1}$, R. Watson ${ }^{2}$, A. O'Neill ${ }^{2}$, V. Donoghue ${ }^{1,3}$, C. O'Donnell ${ }^{1}$, J. Murphy ${ }^{1}$, A. Twomey ${ }^{1}$, E. Molloy ${ }^{4}$
}

${ }^{1}$ National Maternity Hospital, Holles Street, ${ }^{2}$ UCD, School of Medicine and Medical Science, Conway Institute for Biomolecular and Biomedical Science, University College Dublin, ${ }^{3}$ Children's University Hospital, Temple Street, ${ }^{4}$ National Maternity Hospital \& Royal College of Surgeons of Ireland, Dublin,

\section{Ireland}

Aims: To correlate early neutrophil reactive oxygen intermediate (ROI) production with encephalopathy grade and outcome in Neonatal Encephalopathy (NE) infants.

Methods: Serial blood samples were prospectively collected from term infants who required resuscitation following birth and had evidence of exposure to hypoxia-ischaemia in utero $(n=21)$ on day $0,1,2,3$ and 7 of life and from adult controls $(n=12)$. Whole blood ROI production was evaluated via flow cytometry both at baseline and following endotoxin (LPS) stimulation. The study population was divided according to severity of NE; 'Mild' ( $\mathrm{n}=12$ ) and 'Severe' ( $\mathrm{n}=9$ ) based on the Sarnat staging system.

Results: NE infants have raised baseline ROI production compared with adults, irrespective of insult severity. Following endotoxin stimulation, an immunocompetant response is demonstrated in both groups with upregulation to a greater magnitude than seen in adults.

'Severe' NE infants demonstrate significantly elevated baseline levels of ROI production compared to the less severely affected group, which is further elevated following endotoxin stimulation.

\begin{tabular}{|c|c|c|c|c|c|c|c|}
\hline & & ADULT & $\begin{array}{l}\text { NEONATAL } \\
\text { ENCEPHALOPATHY }\end{array}$ & & & & \\
\hline & & & DOL 0 & & DOL 7 & & $p$ value \\
\hline & & & 'Mild' & 'Severe' & 'Mild' & 'Severe' & \\
\hline \multirow[t]{2}{*}{ ROI } & $\mathrm{CON}$ & $\begin{array}{l}18922+/- \\
1685\end{array}$ & $30134+/-5721$ & $\begin{array}{l}39454+/- \\
5522\end{array}$ & $\begin{array}{l}14842+/- \\
2918\end{array}$ & $\begin{array}{l}42852+/- \\
6253\end{array}$ & $<0.05$ \\
\hline & LPS & \begin{tabular}{|l}
$21160+/-$ \\
1777
\end{tabular} & $33495+/-7205$ & $\begin{array}{l}39865+/- \\
6100\end{array}$ & \begin{tabular}{|l}
$34239+/-$ \\
17702
\end{tabular} & $\begin{array}{l}47052+/- \\
6434\end{array}$ & NS \\
\hline
\end{tabular}

[Results]

Conclusions: Term neonates with 'Severe' NE demonstrate significantly elevated ROI production at baseline and following endotoxin stimulation. This illustrates the importance of ROI's in the pathogenesis of neonatal brain injury and the altered, more damaging immune phenotype in this population. 